\title{
PENGARUH SISTEM AKUNTANSI MANAJEMEN DAN \\ GAYA KEPEMIMPINAN TERHADAP HUBUNGAN ANTARA \\ TOTAL QUALITY MANAGEMENT DENGAN KEPUASAN KERJA PADA PERUSAHAAN GO PUBLIK DI BURSA EFEK JAKARTA
}

\author{
Sri Suranta \\ Fakultas Ekonomi Universitas Sebelas Maret \\ E-mail: srisuranta@yahoo.com
}

\section{ABSTRACT}

The purpose of this research is to examine empirically the effect of management accounting systems and leadership style to the relationship between Total Quality Management (TQM) with job satisfaction. The hypothesis is that there are significant influence of management accounting systems and leadership style to relationship between Total Quality Management (TQM) with job satisfaction.

Taken population in this research consists of companies in Indonesian Capital Market Directory (ICMD) year 2004. The samples are middle managers of manufacturing business in ICMD. The hypotheses are examined by moderated regression analysis. Therefore, data must be analyzed by classical assumption, i.e. normality, autocorrelation, and heteroscedasticity.

The examination indicated that all variable are valid and reliable. The classical assumption test fulfilled the classical assumption. Results of hypothesis examination indicate that leadership style has effect to the relationship between Total Quality Management (TQM) with job satisfaction. Nevertheless, the effect of management accounting systems to relationship between Total Quality Management (TQM) with job satisfaction is not supported by the research.

Keyword: Total Quality Management (TQM), Management Accounting Systems, Leadership Style, Job Satisfaction.

\section{PENDAHULUAN}

TQM merupakan inovasi teknologi perusahaan yang dapat digunakan untuk meningkatkan produktivitas baik tenaga kerja maupun kapital (Wruck dan Michael, 1997). Praktik TQM yang efektif memerlukan perubahan dalam sistem akuntansi manajemen. Komponen penting perubahan-perubahan dalam sistem akuntansi manajemen adalah pengumpulan informasi baru, desiminasi informasi lintas hirarki organisasional, sistem reward, tujuan kinerja, dan ukuran kinerja (Sim dan Killough, 1998).

Riset empiris menyatakan bahwa TQM mempunyai pengaruh yang signifikan terhadap outcome individual, misalnya kepuasan kerja. Temuan Boselie dan Ton (2001) yang melakukan riset di Belanda menemukan adanya hubungan konsep "cooperation", "information", "leadership", "salary", "work conditions" dan "goal setting" dengan kepuasan kerja dan keinginan untuk meninggalkan organisasi.

Wasserman et al. (2001) menyatakan bahwa kepemimpinan merupakan faktor penting dalam kinerja organisasional. et al. (2005) menemukan bukti substansial bahwa kepemimpinan mempunyai hubungan positif baik dengan outcomes organisasi maupun individu.

Penelitian ini menggunakan variabel pemoderasi dengan alasan bahwa variabel pemoderasi adalah suatu variabel independen lainnya yang dimasukkan kedalam model karena mempunyai efek kontinjensi dari hubungan variabel independen dan variabel 
dependen sebelumnya. Suatu interaksi negatif terjadi jika hubungan antara variabel independen terhadap variabel dependen lebih negatif untuk nilai variabel pemoderasi yang lebih tinggi (Jogiyanto, 2004: 142-145).

Perbedaan penelitian ini dengan penelitian sebelumnya adalah berikut ini. Penelitian ini memfokuskan TQM, sistem akuntansi manajemen meliputi karakteristik informasi sistem akuntansi manajemen, yaitu informasi broad scope, aggregate, integration, dan integrated yang bermanfaat menurut persepsi para manajer. Hal ini mendasarkan pada penelitian yang dilakukan oleh Boselie dan Ton (2001) bahwa terdapat hubungan konsep informasi, dalam hal ini informasi sistem akuntansi manajemen pada hubungan TQM dengan outcome individual. Berbeda dengan penelitian yang dilakukan oleh Sim dan Killough (1998), Suprantiningrum dan Zulaikha (2003), dan Mardiyah dan Listianingsih (2005), mereka menggunakan komponen sistem akuntansi manajemen yang terdiri atas sistem pengukuran kinerja dan sistem penghargaan (reward). Perbedaan lainnya adalah penelitian ini menggunakan variabel kepemimpinan sebagai variabel kontinjensi (pemoderasi) dalam hubungan TQM dengan outcome organisasi/individu. Hal ini juga mendasarkan pada penelitian yang dilakukan oleh Boselie dan Ton (2001) bahwa terdapat hubungan konsep leadership pada hubungan TQM dengan outcome individual, yaitu kepuasan kerja.

Tujuan penelitian ini dilakukan adalah untuk menemukan bukti empiris apakah interaksi informasi sistem akuntansi manajemen dan gaya kepemimpinan dengan total quality management berpengaruh terhadap kepuasan kerja. Manfaat yang dapat diambil dari penelitian adalah untuk memberi masukan bagi dunia bisnis mengenai pentingnya mempertimbangkan faktor-faktor kondisional, yaitu informasi sistem akuntansi manajemen dan gaya kepemimpinan atas penerapan TQM untuk meningkatkan outcome organisasi/individu, yaitu kepuasan kerja.

\section{TINJAUAN PUSTAKA DAN PENGEMBANGAN HIPOTESIS \\ Teori Kontinjensi}

Hannan dan Freeman (Gerdin, 2005) berpendapat bahwa pendekatan kontinjensi dapat dilakukan jika memenuhi asumsi yang menjadi ide dari pendekatan kontijensi sebagai berikut.

1. Tidak ada satupun desain organisasional yang terbaik, yang terstruktur secara pasti dan tidak terstruktur secara pasti, yang diaplikasikan dalam suatu organisasi.

2. Beragam desain organisasional tersebut memiliki peluang hasil atau kinerja yang sama.

Terpenuhinya kedua asumsi tersebut merupakan syarat untuk dapat dilakukannya pengujian kontinjensi dalam bentuk seleksi natural yaitu dengan menyesuaikan perubahan jumlah populasi (Hannan dan Freeman dalam Gerdin, 2005).

Sistem akuntansi manajemen merupakan suatu pendekatan kontinjensi dari faktor kondisional yang digunakan dalam penelitian sebagai variabel yang memoderasi suatu hubungan. Sesuai dengan pendekatan kontinjensi, Otley dalam Nazaruddin (1998), pendekatan kontinjensi akuntansi manajemen didasarkan premis bahwa tidak ada sistem akuntansi manajemen secara universal selalu tepat digunakan seluruh organisasi, namun sistem akuntansi manajemen hanya sesuai (fit) untuk suatu konteks atau kondisi tertentu saja. Teori kontinjensi dalam metoda penelitian mengargumenkan bahwa efektivitas informasi sistem akuntansi manajemen tergantung eksistensi perpaduan antara organisasi dengan lingkungannya (Mardiyah dan Listianingsih, 2005).

Sistem akuntansi manajemen sering digunakan sebagai mekanisme untuk memotivasi dan mempengaruhi perilaku karyawan dalam berbagai cara yang akan memaksimalkan kesejahteraan organisasi dan karyawan. Sistem akuntansi manajemen sebagai alat kontrol organisasi dan alat yang efektif menyediakan informasi yang bermanfaat guna memprediksi konsekuensi 
yang mungkin terjadi berbagai aktivitas yang dilakukan.

Gaya Kepemimpinan merupakan suatu pendekatan kontinjensi dari faktor kondisional yang digunakan dalam penelitian sebagai variabel yang memoderasi suatu hubungan. Sesuai dengan pendekatan kontinjensi, O'Reilly III et al. (2005) menemukan bukti bahwa bahwa kepemimpinan diantara hirarki secara agregat dapat mempengaruhi perubahan strategi. Hal ini berarti perusahaan yang menerapkan strategi baru, misalnya menerapkan TQM akan dapat dipengaruhi oleh kepemimpinan di setiap hirarki organisasi.

\section{TQM, Informasi Sistem Akuntansi} Manajemen, dan Kepuasan Kerja

Boselie dan Ton (2001) melakukan riset mengenai persepsi karyawan terhadap TQM dan pengaruhnya terhadap outcome individual di Belanda dan menemukan adanya hubungan konsep "cooperation", "information", "leadership", "salary", "work conditions" dan "goal setting" dengan kepuasan kerja dan keinginan untuk meninggalkan organisasi.

Hasil penelitian tersebut menunjukkan bahwa perusahaan yang menerapkan teknik TQM secara langsung dapat meningkatkan outcome organisasi maupun individu, yaitu kepuasan kerja setelah penerapan TQM tersebut dipengaruhi oleh informasi sistem akuntansi manajemen yang ada didalam organisasi.

Sistem akuntansi manajemen sering digunakan sebagai mekanisme untuk memotivasi dan mempengaruhi perilaku karyawan dalam berbagai cara yang akan memaksimalkan kesejahteraan organisasi dan karyawan. Sistem akuntansi manajemen sebagai alat kontrol organisasi dan alat yang efektif menyediakan informasi yang bermanfaat guna memprediksi konsekuensi yang mungkin terjadi berbagai aktivitas yang dilakukan (Mardiyah dan Listianingsih, 2005). Berdasar uraian tersebut, hipotesis alternatif yang diajukan adalah berikut ini.

$\mathrm{Ha}_{1}$ : Interaksi antara penerapan TQM dan informasi akuntansi manajemen berpengaruh terhadap kepuasan kerja.

\section{Gambar 1}

Model Pengaruh Interaksi TQM dan Informasi Akuntansi Manajemen terhadap Kinerja Manajerial dan Kepuasan Kerja

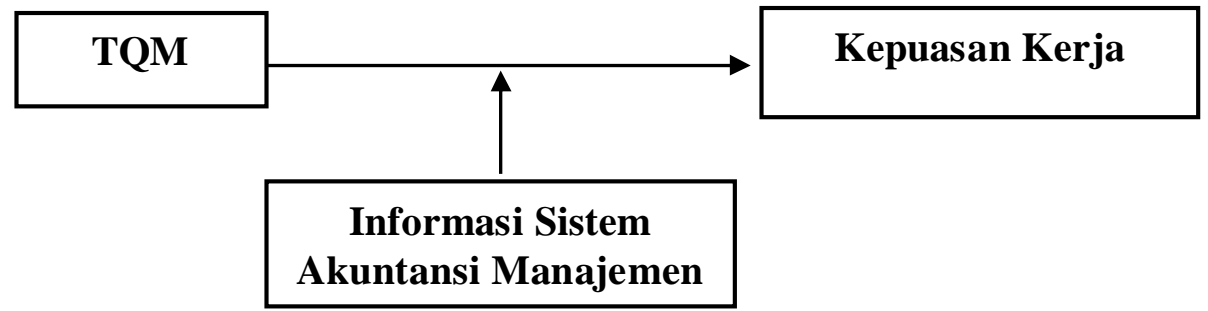

TQM, Gaya Kepemimpinan, dan keinginan untuk meninggalkan organisasi, Kepuasan Kerja hipotesis alternatif yang diajukan berikut ini.

Berdasar penelitian O'Reilly III et al. (2005), Wasserman et al. (2001), dan penelitian yang dilakukan oleh Boselie dan $\mathrm{Ha}_{2}$ : Interaksi antara penerapan TQM dan gaya kepemimpinan berpengaruh terhadap kepuasan kerja. Ton (2001) yang menemukan hubungan antara TQM dan konsep kontekstual, yaitu leadership terhadap kepuasan kerja dan 
Gambar 2

Model Pengaruh Interaksi TQM dan Gaya Kepemimpinan terhadap Kinerja Manajerial dan Kepuasan Kerja

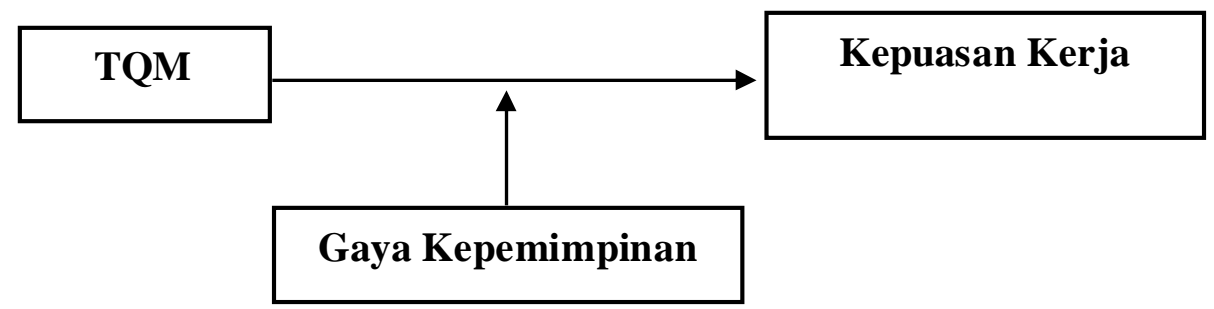

\section{METODE PENELITIAN}

\section{Populasi dan Sampel}

Penelitian ini menurut metodenya merupakan penelitian survei. Penelitian survei merupakan penelitian yang mengambil sampel dari suatu populasi dan menggunakan kuesioner sebagai alat pengumpulan datanya. Survei (survey) atau lengkapnya self-administrated survey adalah metode pengumpulan data primer dengan memberikan pertanyaan-pertanyaan kepada responden individu (Jogiyanto, 2004).

Populasi adalah wilayah generalisasi yang terdiri atas objek/subjek yang mempunyai kualitas dan karakteristik tertentu yang ditetapkan oleh peneliti untuk dipelajari lalu ditarik kesimpulan (Sugiyono, 2001). Populasi dalam penelitian ini adalah manajer tingkat menengah pada perusahaan di Indonesia.

Sampel adalah bagian dari jumlah dan karakteristik yang dimiliki oleh populasi tersebut (Sugiyono, 2001). Pemilihan sampel menggunakan metode purposive sampling. Pengambilan sampel bertujuan (purposive sampling) dilakukan dengan mengambil sampel dari populasi berdasarkan suatu kriteria tertentu, kriteria yang digunakan dapat berdasarkan pertimbangan (judgment) tertentu atau jatah (quota) tertentu (Jogiyanto, 2004). Subjek penelitian yang dijadikan sampel adalah manajer tingkat menengah pada perusahaan-perusahaan manufaktur di Indonesia yang diseleksi dari Index Capital Market Directory 2004, dengan alasan: a) perusahaan yang menerapkan TQM biasanya perusahaan manufaktur, b) manajer tingkat menengah merupakan pelaksana manajemen puncak yang mampu berinteraksi dengan karyawan dan manajemen puncak, dan c) biasanya mereka terlibat langsung dengan kebijakan yang dilaksanakan oleh manajemen puncak.

\section{Pengumpulan Data}

Data yang digunakan dalam penelitian ini adalah data primer. Menurut Sekaran (2000), data primer adalah data yang diperoleh secara langsung dari individuindividu, kelompok-kelompok tertentu, dan juga responden yang telah ditentukan secara spesifik yang memiliki data secara spesifik dari waktu ke waktu. Data primer penelitian ini diperoleh melalui survei, yaitu dengan cara menyebar kuesioner dengan menggunakan jasa pos (mail survey). Survei pos (mail survey) merupakan survei yang pertanyaan-pertanyaannya diirimkan kepada responden lewat pos atau fax atau cara pengiriman yang lain (Jogiyanto, 2004).

Data penelitian ini diperoleh melalui kuesioner yang diberikan kepada responden sesuai prosedur pengumpulan data yang direncanakan. Kuesioner yang disebarkan sebanyak 612 eksemplar yang terdistribusi di 153 perusahaan manufaktur se-Indonesia yang terdapat dalam Indonesian Capital Market Directory (ICMD) tahun 2004. Penyebaran kuesioner dimulai pada pertengahan bulan Juli 2006 sampai dengan pertengahan bulan September 2006. Setiap perusahaan diberikan 4 eksemplar kuesioner yang ditujukan kepada middle management, misalnya: Manajer Keuangan, Manajer Pemasaran, Manajer Produksi dan Manajer Sumber Daya Manusia. 
Dari 612 eksemplar kuesioner yang disebarkan ternyata kembali sebanyak 33 eksemplar. Dari 33 eksemplar setelah diperiksa 2 eksemplar tidak dapat dianalisis karena perusahaan tidak menerapkan TQM. Jumlah total kuesioner yang dapat dianalisis sebanyak 31 eksemplar.

Tabel 1

Jumlah Kuesioner yang Disebar, Kembali, Tidak Dapat Dianalisis dan Dapat Dianalisis

\begin{tabular}{lcc}
\hline Keterangan & Jumlah & $\%$ \\
\hline Kuesioner Disebar & 612 & 100 \\
Kuesioner Kembali & 33 & 5,4 \\
Kuesioner tidak dapat dianalisis & 2 & 0,4 \\
Kuesioner Dianalisis & 31 & 5 \\
Sumber: data primer yang diolah & &
\end{tabular}

Tabel 2

Data Responden yang Mengembalikan Kuesioner dan Dapat Dianalisis

\begin{tabular}{clcc}
\hline No & \multicolumn{1}{c}{ Perusahaan } & Jumlah & \% \\
\hline 1 & PT. Mustika Ratu & 4 & 100 \\
2 & PT. Semen Gresik (Persero) & 2 & 50 \\
3 & PT. Dankos Laboratories & 3 & 75 \\
4 & PT. Citra Tubindo Tbk. & 4 & 100 \\
5 & PT. Astra Otoparts Tbk. & 4 & 100 \\
6 & PT. Pyridam Farma Tbk. & 4 & 100 \\
7 & PT. Pelangi Indah Comindo & 1 & 25 \\
8 & PT. Tira Austenite Tbk. & 1 & 25 \\
9 & PT. Dynaplast Tbk. & 2 & 50 \\
10 & PT. IMSI Tbk. & 1 & 25 \\
11 & PT. Tembaga Mulia Semanan Tbk. & 1 & 25 \\
12 & PT. Surya Kertas & 2 & 25 \\
13 & PT. Polychem Indonesia & 1 & 50 \\
14 & PT. HM Sampoerna & $\mathbf{3 1}$ & 25 \\
\hline TOTAL & & & $\mathbf{5 \%}$ \\
\hline
\end{tabular}

Sumber: data primer yang diolah

\section{Definisi Operasional Variabel dan \\ Pengukuran \\ Variabel Independen \\ Total Quality Management (TQM)}

Total Quality Management dalam penelitian ini adalah suatu filosofi yang menekankan peningkatan proses pemanufakturan secara berkelanjutan dengan mengeliminasi pemborosan, meningkatkan kualitas, mengembangkan ketrampilan, dan mengurangi biaya produksi (Sim dan Killough, 1998). Variabel TQM ini mengukur persepsi manajer secara individual mengenai penerapan teknik TQM di 
lingkungan perusahaannya. Variabel TQM diukur dengan memasukkan elemen utama manajemen kualitas yaitu orientasi proses, elemen manusia serta budaya kualitas. Instrumen yang digunakan adalah instrumen yang dikembangkan oleh Ahire (1996). Instrumen ini juga digunakan oleh Rahayu (1998) dalam tesisnya. Instrumen ini terdiri dari 6 pertanyaan yang diukur dengan menggunakan skala interval. Skala yang

Tidak seiuju", sampai dengan 5 yang menyatakan "sangat setuju".

\section{Informasi Sistem Akuntansi Manajemen}

Sistem akuntansi manajemen dalam penelitian ini adalah sistem yang mengumpulkan data operasional dan finansial, memprosesnya, menyimpannya dan melaporkannya kepada pengguna, yaitu para pekerja, manajer, dan eksekutif (Atkinson et al. dalam Desmiyawati, 2001). Variabel informasi sistem akuntansi manajemen diukur dengan menggunakan instrumen yang dikembangkan oleh Chenhall dan Morris (1986) dan telah digunakan beberapa peneliti yang lain, misalnya Abbernathy dan Guthrie (1994); Chong dan Chong (1997); Nazaruddin (1998); Supardiyono (1999); Mardiyah dan Gudono (2000) dalam Imron (2004), Muslichah (2003), Meildawati (2003) dan Imron (2004).

Chenhall dan Morris (1986) menyatakan bahwa terdapat empat karakteristik informasi yang dihasilkan oleh sistem akuntansi manajemen, yaitu broad scope, timeliness, aggregate, dan integrated yang bermanfaat menurut persepsi para manajer. Instrumen ini terdiri dari 19 pertanyaan yang diukur dengan menggunakan skala interval. Skala yang digunakan mulai 1 yang menyatakan "tidak penting", sampai dengan 7 yang menyatakan "sangat penting". Ke-19 pertanyaan tersebut terbagi dalam: 5 (lima) pertanyaan mengenai instrumen yang bersifat broad scop, 4 (empat) pertanyaan mengenai instrumen yang bersifat timelines, 7 (tujuh) pertanyaan mengenai instrumen yang bersifat aggregation dan 3 (tiga) pertanyaan mengenai instrumen yang bersifat integration.

\section{Gaya Kepemimpinan}

Gaya kepemimpinan dalam penelitian ini merupakan derajat hubungan antara seseorang dengan teman sekerjanya, termasuk teman sekerja yang tidak disukai (Fiedler dalam Sumarno, 2005). Instrumen untuk mengukur variabel ini diadopsi dari Fiedler (1967) yang dikenal dengan nama Least Preferred Cowoker (LPC). Instrumen ini juga digunakan oleh Sumarno (2005). Instrumen ini diukur dengan menggunakan skala interval. Skala yang digunakan mulai 1 (satu) sampai dengan 7 (tujuh).

\section{Variabel Dependen \\ Kepuasan Kerja}

Kepuasan kerja didalam penelitian ini merupakan keadaan emosi positif atau menyenangkan yang diakibatkan oleh penghargaan atas pekerjaan seseorang atau pengalaman pekerjaannya (Locke dalam Wasisto dan Sholihin, 2004). Variabel ini diukur dengan menggunakan instrumen Minnesota Satisfaction Questionnaire (MSQ) yang pendek yaitu sebanyak 20 item pertanyaan. Instrumen ini juga digunakan oleh peneliti lain, misalnya Aisyah dan Sholihin (2004) dan Wasisto dan Sholihin (2004). Instrumen ini diukur dengan menggunakan skala interval. Skala yang digunakan mulai 1 yang menyatakan "tidak puas" sampai dengan 5 yang menyatakan "benar-benar puas".

\section{ANALISIS DATA DAN PEMBAHASAN Pengujian Data Uji Validitas}

Untuk menguji validitas konstruk dalam penelitian ini, digunakan alat uji pearson correlation. Hasil dari uji ini menunjukkan semua instrumen pada setiap variabel valid, karena nilai signifikansi koefisien pearson lebih kecil dari $\alpha$ yang ditetapkan, yaitu sebesar 0,05 atau nilai koefisien pearson lebih besar dari nilai tabel yang ditetapkan, yaitu sebesar 0,374. 


\section{Uji Reliabilitas}

Untuk menguji reliabilitas data dalam penelitian ini, digunakan teknik Cronbach's alpha. Hasil uji cronbach's alpha menunjukkan bahwa variabel Total Quality Management (TQM), sistem akuntansi manajemen (SAM), gaya kepemimpinan, kepuasan kerja dan kinerja manajerial dikategorikan reliabilitas baik, karena nilai cronbach's alpha lebih besar dari 0,8. Dari hasil uji validitas dan reliabilitas maka variabel yang ada layak untuk dilakukan uji berikutnya.

Tabel 3

Reliabelitas Data Variabel Penelitian

\begin{tabular}{clcc}
\hline No & \multicolumn{1}{c}{ Variabel } & Signifikansi Cronbach' Alpha & Status \\
\hline 1 & TQM & 0,9025 & baik \\
2 & SAM & 0,9610 & baik \\
3 & Gaya Kepemimpinan & 0,9103 & baik \\
4 & Kepuasan Kerja & 0,9321 & baik \\
\hline
\end{tabular}

Sumber: Data Primer Diolah

\section{Uji Asumsi Klasik}

Normalitas

Uji Normalitas dilakukan dengan menggunakan uji Kolmogorov-Smirnov. Dari hasil uji normalitas yang telah dilakukan dapat kita ketahui bahwa variabel Total
Quality Management (TQM), sistem akuntansi manajemen (SAM), gaya kepemimpinan, kepuasan kerja dan kinerja manajerial berdistribusi normal, karena nilai signifikansi K-S lebih besar dari $\alpha$ yang tetapkan, yaitu 0,05 .

Tabel 4

Hasil Uji Normalitas Data Penelitian

\begin{tabular}{clcc}
\hline No & \multicolumn{1}{c}{ Variabel } & Signifikansi $\boldsymbol{K}-\boldsymbol{S}$ & Status \\
\hline 1 & TQM & 0,403 & normal \\
2 & SAM & 0,879 & normal \\
3 & Gaya Kepemimpinan & 0,978 & normal \\
4 & Kepuasan Kerja & 0,949 & normal \\
\hline
\end{tabular}

Sumber: Data Primer Diolah

\section{Multikolinearitas}

Uji Multikolinearitas merupakan suatu alat keadaan dimana variabel-variabel independen dalam persamaan regresi mempunyai hubungan yang kuat satu sama lain (Arsyad, 1997). Menurut Hartmann dan Moers dalam Jogiyanto (2004: 150) bahwa multikolinearitas tidak terjadi untuk tiga variabel interaksi karena koefisien dari interaksi variabel independen dengan variabel pemoderasi tidak sensitif terhadap perubahan dari titik awal skala (misalnya ditransformasikan untuk ditengahkan berdasarkan nilai rata-ratanya) dari variabelin dependen dan variabel pemoderasi, sehingga multikolinearitas tidak terjadi masalah ketika menerapkan analisis regresi pemoderasi.

\section{Heteroskedastisitas}

Heteroskedastisitas berarti penyebaran titik data populasi pada bidang regresi tidak konstan. Situasi heteroskedastisitas akan menyebabkan penafsiran koefisien regresi 
menjadi tidak efisien. Hasil taksiran dapat menjadi kurang dari semestinya, melebihi dari semestinya, atau menyesatkan. Model regresi yang baik, jika varian dari residual satu pengamatan ke pengamatan lain tetap atau homoskedastisitas (Nugroho, 2005). Uji Heteroskedastisitas menggunakan metode grafik scatter plot. Hasil dari gambar scatte rplot menunjukkan penyebaran titik-titik sebagai berikut:

1) Titik-titik data menyebar di atas dan di bawah atau di sekitar angka 0 .
2) Titik-titik data tidak mengumpul hanya di atas atau di bawah saja.

3) Penyebaran titik-titik data tidak membentuk pola bergelombang melebar kemudian menyempit dan melebar.

4) Penyebaran titik-titik data tidak berpola. Berdasar hasil uji heteroskedastisitas, dapat disimpulkan bahwa model regresi linier moderasian terbebas dari asumsi klasik heteroskedastisitas dan layak digunakan dalam penelitian.

Gambar 3

Hasil Uji Heteroskedastisitas

Partial Regression Plot

Dependent Variable: PUAS

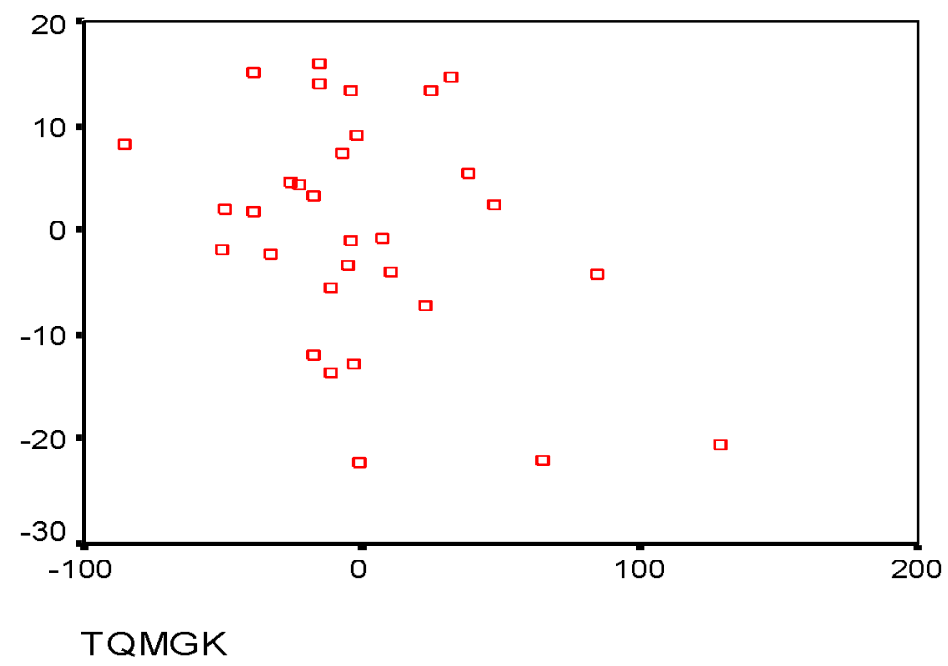

\section{Autokorelasi}

Pengujian autokorelasi dalam penelitian ini menggunakan uji Durbin Watson. Nilai d yang dihasilkan dalam setiap persamaan regresi sebesar 1,706; dan 2,218.Dengan tingkat signifikansi 0,05 , nilai d pada tabel statistik d dari Durbin Watson untuk $\mathrm{K}$ (jumlah variabel independen) $=3$ dan $\mathrm{n}$ (jumlah sampel $)=31$ yaitu nilai $\mathrm{dl}=$ 1,130 dan nilai $\mathrm{du}=1,550$. Dari nilai-nilai tersebut diketahui tidak terjadi autokolerasi sebab d hitung tidak lebih kecil dari du dan tidak lebih besar dari 4-du yaitu 1,550 < 1,$706 ; 2,218<2,450$ yang berarti tidak ada autokorelasi (lampiran tabel 6).

\section{Pengujian Hipotesis dengan Moderated Regression Analysis (MRA)}

Hipotesis penelitian ini diuji dengan alat analisis regresi berganda. Menurut Jogiyanto (2004), model empiris untuk variabel pemoderasi menggunakan model analisis regresi moderasian (moderated regression analysis). Berikut ini hasil analisis regresi pengaruh gaya kepemimpinan dan SAM terhadap hubungan antara Total Quality Management (TQM) dan kepuasan kerja.

\section{Uji Hipotesis Ha1}

Hipotesis $1\left(\mathrm{Ha}_{1}\right)$ dinyatakan bahwa interaksi antara penerapan TQM dan informasi akuntansi manajemen berpengaruh 
terhadap kepuasan kerja. Berdasar tabel 5 di bawah diketahui bahwa variabel interaksi TQM dan SAM memiliki nilai signifikansi $\mathrm{t}$ sebesar 0,064 > 0,05 yang artinya hubungan interaksi tersebut tidak signifikan. Hal ini berarti bahwa tidak ada pengaruh signifikan interaksi TQM dengan SAM terhadap kepuasan kerja.

Tabel 5

Hasil Uji Hipotesis 1

\begin{tabular}{rrrrrrr}
\hline & & $\begin{array}{c}\text { Unstandardized } \\
\text { Coefficients }\end{array}$ & \multicolumn{2}{c}{$\begin{array}{c}\text { Standardized } \\
\text { Coefficients }\end{array}$} & t & Sig. \\
\hline Model & & B & Std. Error & Beta & & \\
\hline 1 & (Constant) & $-24,278$ & 53,124 & & $-0,457$ & 0,651 \\
& TQM & 4,963 & 2,488 & 1,989 & 1,995 & 0,056 \\
& SAM & 0,655 & 0,412 & 1,300 & 1,590 & 0,123 \\
& TQMSAM & $-3,718 \mathrm{E}-02$ & 0,019 & $-2,595$ & $-1,933$ & 0,064 \\
& & & & & &
\end{tabular}

a Dependent Variable: PUAS

\section{Uji Hipotesis Ha}

Hipotesis $2\left(\mathrm{Ha}_{2}\right)$ dinyatakan bahwa interaksi antara penerapan TQM dan gaya kepemimpinan berpengaruh terhadap kepuasan kerja. Berdasar tabel 6 di bawah diketahui bahwa variabel interaksi TQM dan gaya kepemimpinan memiliki nilai signifikansi $\mathrm{t}$ sebesar $0,043<0,05$ yang artinya hubungan interaksi tersebut signifikan. Hal ini berarti bahwa ada pengaruh signifikan interaksi TQM dengan gaya kepemimpinan terhadap kepuasan kerja. Namun, koefisien nilai t negatif yaitu sebesar $\mathrm{t}=-2,120$, yang berarti semakin tinggi pengaruh gaya kepemimpinan semakin besar pengaruh negatif TQM terhadap kepuasan kerja.

Tabel 6

Hasil Uji Hipotesis 2

\begin{tabular}{rrrrrr}
\hline & $\begin{array}{c}\text { Unstandardized } \\
\text { Coefficients }\end{array}$ & \multicolumn{2}{c}{$\begin{array}{c}\text { Standardized } \\
\text { Coefficients }\end{array}$} & t & Sig. \\
\hline Model & B & Std. Error & Beta & & \\
\hline 1 (Constant) & $-150,321$ & 97,018 & & $-1,549$ & 0,133 \\
TQM & 8,948 & 4,219 & 3,587 & 2,121 & 0,043 \\
PIMPIN & 2,401 & 1,076 & 3,081 & 2,230 & 0,034 \\
TQMGK & $-9,812 \mathrm{E}-02$ & 0,046 & $-5,132$ & $-2,120$ & 0,043 \\
\hline
\end{tabular}

a Dependent Variable: PUAS

\section{Pembahasan Hasil Analisis}

Hasil analisis regresi berganda moderasian (moderated regression analysis) tidak dapat menolak tiga hipotesis alternatif, yaitu Ha2. Hal ini berarti bahwa ada pengaruh signifikan gaya kepemimpinan terhadap hubungan antara Total Quality Management (TQM) dengan kepuasan kerja. 
Namun penelitian ini menolak Hal bahwa tidak ada pengaruh signifikan sistem akuntansi manajemen (SAM) terhadap hubungan antara Total Quality Management (TQM) dengan kepuasan kerja.

Hasil penelitian ini konsistensi dengan hasil penelitian Boselie dan Ton (2001) yang menyatakan bahwa terdapat hubungan konsep "cooperation", "information", "leadership", "salary", "work conditions" dan "goal setting" dengan kepuasan kerja. Hasil penelitian ini juga konsistensi dengan et al. (2005) yang menemukan bukti substansial bahwa kepemimpinan mempunyai hubungan positif baik dengan outcomes organisasi maupun individu.

\section{SIMPULAN DAN SARAN}

Berdasar hasil analisis data dan pengujian hipotesis yang telah dilakukan, dapat disimpulkan berikut ini.

1. Ada pengaruh yang signifikan interaksi antara total quality management dengan gaya kepemimpinan terhadap kepuasan kerja.

2. Tidak ada pengaruh pengaruh yang signifikan interaksi antara total quality management dengan sistem akuntansi manajemen terhadap kepuasan kerja.

3. Perusahaan yang menerapkan strategi baru, misalnya total quality management dapat mempengaruhi outcome individu, misalnya kepuasan kerja bila didukung faktor kondisional yang lain, misalnya sistem akuntansi manajemen dan gaya kepemimpinan.

Penelitian ini memiliki beberapa keterbatasan. Oleh karena itu peneliti memberikan saran perbaikan untuk penelitian berikutnya.

1. Instrumen untuk mengukur kinerja manajerial merupakan self-rating yang bisa menimbulkan leniency bias, yaitu kecenderungan memberikan skor yang lebih tinggi daripada keadaan sebenarnya. Penelitian mendatang bisa dikembangkan dengan menggunakan ukuran kinerja organisasi, misalnya dengan menggunakan ROA (Return On Assets) atau ROI (Return On Investment).

2. Pengiriman kuesioner melalui pos tidak mendapatkan respon yang baik serta tidak dapat dikendalikan karena peneliti tidak bisa secara langsung bertemu dengan responden. Hal tersebut menyebabkan persentase tingkat pengembalian kuesioner melalui pos sangat kecil. Untuk penelitian mendatang, sebaiknya peneliti melakukan reminder kepada responden yang lebih intensif, dengan cara setelah kuesioner dikirim, responden dihubungi beberapa kali lewat telepon untuk memastikan bahwa kuesioner sampai tujuan, kuesioner telah diisi dan dikembalikan lagi kepada peneliti.

\section{DAFTAR PUSTAKA}

Ahire, Sanjay L, Golhar, Damodar Y, Waller, and Mathew A. Al. 1996. Development and Validation of TQM Implementation Constructs. Decision Sience, 27: 23-56.

Aisyah, Mimin Nur dan Mahfud Sholihin. 2004. The Role of Organizational Commitment and Job-Relevant Information on The Relationship between Budgetary Participation and Job Satisfaction. Simposium Nasional Akuntansi VII (SNA VII): Denpasar, 2-3 Desember.

Arsyad, Lincolin. 1997. Peramalan Bisnis. Yogyakarta: BPFE.

Banker, R. D., G. Potter and R. G. Schroeder. 1993. Reporting Manufacturing Performance Measures to Workers: An Empirical Study. Journal of Management Accounting Research 5 (Fall): 33-55.

Besterfield, Dale H, Carol BesterfieldMichna, Glen H. Besterfiled dan Mary Besterfield-Sacre. 2003. Total 
Quality Management. Third Edition. New Jersey: Prentice Hall.

Boselie, Paul, and Ton Van Der Weile. 2001. Employee Perceptions of HRM and TQM and the Effects of Satisfaction and Intention to Leave. ERIM Report Series Reference No. 200142-ORG.

Chenhall, RH. (2003). Management Control Systems Design within Its Organizational Context: Findings from Contingency-based Research and Directions for The Future. Accounting, Organizations and Society 28, pp. 127-168.

Chenhall, Robert H., and Morris, Deigen. 1986. The Impact of Structure, Enviroment, and Interdependence on the Perceived Usefulness of Management Accounting System. The Accounting Review, Vol. LXI, No.1, pp. 16-33.

Desmiyawati. 2001. Pengaruh Strategi Bisnis dan Ketidakpastian Lingkungan terhadap Hubungan antara Karakteristik Informasi Sistem Akuntansi Manajemen dengan Kinerja Organisasi. Thesis S2. Yogyakarta: Program Pasca Sarjana UGM.

Fiedler, F.E. (1964). A Contingency Model of Leadership Effectiveness. Advances in Experimental Social Psychology. L. Berkowitz. New York: Academic Press: pp. 149-190.

(1967). A Theory of Leadership Effectiveness. New York: McGraw-Hill.

(1971). Leadership. New York: General Learning Press.

(1981). Leader Attitudes and Group Effectiveness. Westport, CT: Greenwood Publishing Group.
Gerdin, Jonas. 2005. Conceptualizations of Contigency Fit in Management Accounting ResearchCorrespondence Between Statistical Models Used and Core Contigency Theory Assumptions. www.cf.uk/carbs/research/cafbru/200 5ISCAR

Gibson, James L. 1997. Organization, Behavior, Structure, Process. $9^{\text {th }}$ edition. Chicago: Irwin.

Gujarati, Damodar N. 2003. Basics Econometrics. New York : Mc Graw Hill.

Hackman, J. R. And Wegeman, R. (1995). Total Quality Management: Empirical, Conceptual and Practical Issues. Administrative Science Quarterly, 40, pp. 309-342.

Handoko, T Hani. 1986. Manajemen. Edisi Kedua. Yogyakarta.: BPFE UGM

Handoko, T. Hani. 2001. Manajemen Personalia dan Sumberdaya Manusia. Edisi Kedua. Yogyakarta: BPFE UGM

Hardini, Sri. 2001. Hubungan Pengaruh Gaya Kepemimpinan terhadap Prestasi Kerja Pegawai KPKN Yogyakarta. Skripsi S-1 Fakultas Ekonomi, UGM.

Herbowo, 2005. Pengantar Manajemen. Yogyakarta: AA YKPN

Ikhsan, Arfan dan Rasdianto. 2005. Pengaruh Intervening Penggunaan Sistem Akuntansi Manajemen dalam Hubungan Antara Intensitas Persaingan Pasar terhadap Kinerja Unit Perusahaan. Simposium Nasional Akuntansi VIII (SNA VIII): Solo, 15-16 September. 
Imron, Moch. 2004. Pengaruh Ketidakpastian Lingkungan dan Strategi Bisnis terhadap Hubungan antara Karakteristik Informasi Sistem Akuntansi Manajemen Broadscope dengan Kinerja Unit Bisnis Strategis. Simposium Nasional Akuntansi VII (SNA VII): Denpasar, 2-3 Desember.

Indriantoro, Nur dan Bambang Supomo. 1998. Metodologi Penelitian Bisnis untuk Akuntansi dan Manajemen. Edisi Pertama. Yogyakarta: BPFE.

Ittner, CD and Larcker, DF. 1995. Total Quality Management and The Choice of Information and Reward Systems. Journal of Accounting Research 33 (suppl.), pp. 1-34.

Jogiyanto, H. M. 2004. Metodologi Penelitian Bisnis: Salah Kaprah dan Pengalaman-pengalaman. Edisi 2004/2005. Yogyakarta: BPFE.

Luthans, Fred. 1998. Organizational Behavior. New York: Mc Graw Hill

Mahoney, T. A., T. H. Jerdee and S. J. Carroll (1963). Development of Managerial Performance: A Research Approach. Cincinnati: South Western Publ. Co.

Mardiyah, Aida Ainul dan Listianingsih (2005). Pengaruh Sistem Pengukuran Kinerja, Sistem Reward, dan Profit Center terhadap Hubungan antara Total Quality Management dengan Kinerja Manajerial. Simposium Nasional Akuntansi VIII (SNA VIII): Solo, 1516 September.

Meildawati. 2003. Pengaruh Efektivitas Sistem Akuntansi Manajemen terhadap Peningkatan Kinerja Manajerial: $\quad$ Ketidakpastian Lingkungan dan Struktur
Organisasional sebagai Variable Moderating. Skripsi S1. Tidak dipublikasikan. Surakarta: UNS.

Mowen, Maryanne M., and Hansen R. Don. 2000. Management Accounting. International Thomson Publishing, pp. 434-457.

Mulyadi (1998). Total Quality Management. Edisi I. Yogyakarta: Aditya Media.

dan Johny (1999). Sistem Perencanaan dan Pengendalian Manajemen: Sistem Pelipat Ganda Kinerja Perusahaan. Edisi I. Yogyakarta: Aditya Media.

Muslichah (2003). The Effect of Contextual Variables on Management Accounting System Characteristics and Managerial Performance. Simposium Nasional Akuntansi VI (SNA VI): Surabaya, 16-17 Oktober.

Nazaruddin, Ietje. 1998. Pengaruh Desentralisasi dan Karakteristik Informasi Sistem Akuntansi Manajemen terhadap Kinerja Manajerial. Jurnal Riset Akuntansi Indonesia, Vol. 1, No. 2, hal. 141160.

Nugroho, Bhuono Agung (2005). Strategi Jitu Memilih Metode Statistik Penelitian dengan SPSS. Edisi 1. Yogyakarta: Penerbit Andi.

Jennifer Chatman. 2005. How Leadership Matters: The Effects of Leadership Alignment on Strategic Execution. Stanford GSB Research Paper No. 1895, June.

Prasetyo, Priyono Puji. 2002. Pengaruh Locus of Control terhadap Hubungan Antara Ketidakpastian Lingkungan dengan Karakteristik Informasi Sistem Akuntansi 
Manajemen. Jurnal Riset Akuntansi Indonesia, Vol. 5, No. 1, hal. 119136.

Rahayu, Fatik (1998). TQM dan Dampaknya terhadap Kepuasan Kerja. Tesis S2. Tidak dipublikasikan. Yogyakarta: UGM.

Santoso, Singgih (2001). SPSS Versi 10: Mengolah Data Statistik secara Profesional. Jakarta: PT Elex Media Komputindo.

Sekaran, Uma (2000). Research Method for Business: A Skill Building Approach. Third Edition. New York: John Wiley \& Sons, Inc.

Shank, J.K. and V. Govindarajan. 1993. Strategic Cost Management: The New Tool for Competitive Advantage. New York: Free Press.

Sim, K.L., and L.N. Killough. 1998. The Performance Effect of Complementaries between Manufacturing Practice and Management Accounting System. Journal of Management Accounting Research 10 (Fall): pp. 325-346.

Sugiyono (2001). Metode Penelitian Bisnis. Bandung: CV Alfabeta.

Sumarno, J. (2005). Pengaruh Komitmen Organisasi dan Gaya Kepemimpinan terhadap Hubungan anatar Partisipasi Anggaran dan Kinerja Manajerial. Simposium Nasional Akuntansi VIII (SNA VIII): Solo, 15-16 September.
Suprantiningrum dan Zulaikha (2003). Pengaruh Total Quality Management terhadap Kinerja Manajerial dengan Sistem Pengukuran Kinerja dan Sistem Penghargaan (Reward) sebagai Variabel Moderating. Simposium Nasional Akuntansi VI (SNA VI): Surabaya, 16-17 Oktober.

Syptak, Marslanddan dan Ulmer. 1999. Job Satisfaction: Putting Theory Into Practice. American Academy of Phisicians. Vol. 6, No. 9

Wartono. 2005. Metodologi Penelitian. Modul Perkuliahan Metodologi Penelitian. Universitas Sebelas Maret: Surakarta.

Wasisto, Arief dan Mahfud Sholihin. 2004. Peran Partisipasi Penganggaran dalam Hubungan antara Keadilan Prosedural dengan Kinerja Manajerial dan Kepuasan Kerja. Simposium Nasional Akuntansi VII (SNA VII): Denpasar, 2-3 Desember.

Wasserman, Noam, Nitin Nohria dan Bharat N. Anand. 2001. When Does The Leadership Matter? The Contingent Opportunities View of CEO Leadership. Startegy Unit Working Paper No. 02-04; Harvard Business School Working Paper No. 01-063.

Wruck, Karen H., and Michael C. Jensen. 1997. Science, Specific Knowledge, and Total Quality Management. Journal of Applied Corporate Finance, Vol. 10, No. 2 (Summer). 